Article

\title{
Determination of Non-Steroidal Anti-Inflammatory Drugs in Animal Urine Samples by Ultrasound Vortex-Assisted Dispersive Liquid-Liquid Microextraction and Gas Chromatography Coupled to Ion Trap-Mass Spectrometry
}

\author{
Pasquale Avino(D, Ivan Notardonato, Sergio Passarella and Mario Vincenzo Russo *(D) \\ Department of Agricultural, Environmental and Food Sciences, University of Molise, via De Sanctis, \\ I-86100 Campobasso, Italy; avino@unimol.it (P.A.); ivan.notardonato@unimol.it (I.N.); \\ sergio.passarella@studenti.unimol.it (S.P.) \\ * Correspondence: mvrusso@unimol.it; Tel.: +39-0874-404-717
}

Received: 26 May 2020; Accepted: 29 June 2020; Published: 6 August 2020

Featured Application: The paper would like to show an easy, rapid, and affordable protocol to be used for determining four non-steroidal anti-inflammatory drugs (NSAIDs) (i.e., acetylsalicylic acid, ibuprofen, naproxen, and ketoprofen) in urine samples at trace levels. The method could be routinely used in several situations, from medicine and veterinary to doping issues.

\begin{abstract}
A low solvent consumption method for the determination of non-steroidal anti-inflammatory drugs (NSAIDs) in animal urine samples is studied. The NSAIDs were extracted with $\mathrm{CH}_{2} \mathrm{Cl}_{2}$ by the ultrasound vortex assisted dispersive liquid-liquid microextraction (USVA-DLLME) method from urine samples, previously treated with $\beta$-glucuronidase/acrylsulfatase. After centrifugation, the bottom phase of the chlorinated solvent was separated from the liquid matrix, dried with $\mathrm{Na}_{2} \mathrm{SO}_{4}$, and derivatized with $\mathrm{N}, \mathrm{O}$-bis(trimethylsilyl)trifluoroacetamide (BSTFA) + trimethylchlorosilane (TMCS) $(99+1)$. After cooling at room temperature, the solution was concentrated under nitrogen flow, and $1 \mu \mathrm{L}$ of solution was analyzed in gas chromatography/ion trap-mass spectrometry (GC-IT-MS). The enrichment factor was about 300-450 times and recoveries ranged from 94.1 to $101.2 \%$ with a relative standard deviation (RSD) of $\leq 4.1 \%$. The USVA-DLLME process efficiency was not influenced by the characteristics of the real urine matrix; therefore, the analytical method characteristics were evaluated in the range $1-100 \mathrm{ng} \mathrm{mL}^{-1}\left(\mathrm{R}^{2} \geq 0.9950\right)$. The limits of detection (LODs) and limits of quantification (LOQs) were between 0.1 and $0.2 \mathrm{ng} \mathrm{mL}^{-1}$ with $\mathrm{RSD} \leq 4.5 \%$ and between 4.1 and $4.7 \mathrm{ng} \mathrm{mL}^{-1}$ with RSD $\leq 3.5 \%$, respectively, whereas inter- and intra-day precision was $3.8 \%$ and $4.5 \%$, respectively. The proposed analytical method is reproducible, sensitive, and simple.
\end{abstract}

Keywords: non-steroidal anti-inflammatory drug (NSAID); urine; doping analysis; dispersive liquid-liquid microextraction (DLLME); gas chromatography mass spectrometry (GC-MS)

\section{Introduction}

Anti-inflammatory drugs, used for reducing inflammation, are of two types, i.e., cortisone-based and non-steroidal anti-inflammatory drugs (NSAIDs). The latter are, in all likelihood, the best known and most used category of anti-inflammatory drugs in therapy [1]. NSAIDs are a wide class of drugs showing anti-inflammatory, analgesic, and antipyretic action and include some of the best-known molecules used to fight pain [2]: ibuprofen, nimesulide, ketoprofen, naproxen, and diclofenac. They are 
able to stop the inflammation process by their mechanism of action, i.e., interfering with the synthesis of prostanoids; molecules that play a fundamental role in these processes [3]. To do this, the NSAIDs block one or more passages of the metabolism of arachidonic acid, which is the precursor of prostaglandins [4]. Further, NSAIDs can also be used as pain relievers and antipyretics $[5,6]$.

NSAIDs are associated with a small increase in the risk of a heart attack, stroke, or heart failure [7]. However, even in this case, the real danger depends on the type of molecule taken, the duration of the treatment, and the doses taken. Short-term use can instead trigger less serious but sometimes serious adverse effects, such as ulcers, gastric bleeding, and kidney damage [8-10]. In addition, NSAIDs can trigger allergic reactions and interfere with the activity of antihypertensive drugs [11].

Furthermore, NSAIDs are commonly used in animal medicine in different inflammatory situations (e.g., for curing musculoskeletal problems in equines) [12-14]. On the other hand, these drugs are improperly used for masking inflammation and pain of an animal, especially before horse racing. NSAIDs are substances prohibited in horse competitions and are considered one of the main doping agents [15-18]. For instance, salicylic acid, a NSAID used for the treatment of pain and fever, has an allowed threshold of $750 \mu \mathrm{g} \mathrm{mL} \mathrm{m}^{-1}$ in urine, or $6.5 \mu \mathrm{g} \mathrm{mL} \mathrm{m}^{-1}$ in plasma, for equines [19].

NSAIDs are considered safe drugs, but acute overdose or chronic abuse can give serious toxic effects $[20,21]$. They are weak in acid $\left(\mathrm{pK}_{\mathrm{a}} 3-5\right)$ and some of them show short half-lives (e.g., ibuprofen 2-3 h [22]), whereas others show long half-lives (e.g., phenylbutazone residual can also be detected after $24 \mathrm{~h} \mathrm{[23]).} \mathrm{A} \mathrm{screening} \mathrm{procedure} \mathrm{is} \mathrm{necessary} \mathrm{for} \mathrm{detecting} \mathrm{such} \mathrm{drugs} \mathrm{in} \mathrm{urine} \mathrm{samples.}$ Different analytical methods are present in literature, mainly based on liquid-liquid extraction (LLE) or solid-phase extraction (SPE), followed by chromatographic methods (i.e., HPLC with fluorescence detector HPLC-FLD, HPLC-diode array detection (DAD), gas chromatography mass spectrometry (GC-MS), GC-MS/MS, UHPLC-MS/MS, capillary electrophoresis CE-DAD, and CE-MS) [20,24-33]. Further, a derivatization step is necessary before the GC-MS analysis [30,31,34].

Recently, Rezaee et al. introduced the dispersive liquid-liquid microextraction (DLLME) [35]. The extraction is based on the addition of both an immiscible solvent with higher density to the aqueous sample and a dispersant solvent for increasing the contact between the two immiscible solvents. For many years, researchers have deepened this method by applying it to different matrices [36-38], especially for avoiding (at least, for reducing) the use of highly toxic chloro-solvents [39]. In this way, several protocols based on ultrasound vortex assisted DLLME (USVA-DLLME) for determining toxic compounds in foodstuffs have been investigated and set up [40-44].

The aim of this study was to develop a simple method for the simultaneous screening and confirmation of four NSAIDs, i.e., acetylsalicylic acid (ASA), ibuprofen (IBP), naproxen (NAP), and ketoprofen $(\mathrm{KPF})$, in animal urine samples. The entire procedure, not previously reported in literature, starts with the extraction procedure, i.e., the USVA-DLLME method, followed by the NSAID derivatization step with N,O-bis(trimethylsilyl)trifluoroacetamide (BSTFA)-trimethylchlorosilane (TMCS) to form the relative trimethylsilyl (TMS) derivates: gas chromatography coupled with an ion trap-mass spectrometry detector (GC-IT-MS) has allowed us to detect the NSAID residues in real samples.

\section{Materials and Methods}

\subsection{Materials}

Ethanol, $\mathrm{C}_{2} \mathrm{Cl}_{2}, \mathrm{CHCl}_{3}, \mathrm{C}_{2} \mathrm{H}_{4} \mathrm{Cl}_{2}, \mathrm{C}_{2} \mathrm{H}_{2} \mathrm{Cl}_{4}$, and acetone were of pesticide grade (Carlo Erba, Milan, Italy), whereas $\mathrm{NaCl}$, acetic acid, $\mathrm{NaOH}, \mathrm{HCl}$, and Anhydrous $\mathrm{Na}_{2} \mathrm{SO}_{4}$ were of analytical grade (Carlo Erba). Standards of acetylsalicylic acid, ibuprofen, naproxen, and ketoprofen were purchased as powder from Sigma-Aldrich (Milan, Italy), whereas anthracene, used as the internal standard (IS), was provided by LabService Analytical (Anzola Emilia, Bologna, Italy). Beta-glucuronidase/arylsulfatase and BSTFA-TMCS $(99+1)$ solutions were given by Sigma-Aldrich. 
The solutions $\left(1 \mathrm{mg} \mathrm{mL} \mathrm{m}^{-1}\right)$ of each analyte, i.e., acetylsalicylic acid, ibuprofen, naproxen, and ketoprofen (Table 1), were prepared in acetone. These solutions were further diluted for preparing final working standard solutions for spiking both the blank solutions (simulated urine samples) and real samples.

Table 1. The non-steroidal anti-inflammatory drugs (NSAIDs) investigated in this paper, with their corresponding abbreviations, Chemical Abstracts Service (CAS) number, chemical structure, molecular weight (MW), target, and qualifier ions (selected ion monitoring (SIM), abundance 100\%).

\begin{tabular}{ccccccc}
\hline Compound $^{\mathbf{a}}$ & \# CAS & Formula & MW & Target Ion $^{\mathbf{b}}$ & Qualifier Ion $^{\mathbf{b}}$ & II Ion $^{\mathbf{b}}$ \\
\hline ASA & $50-78-2$ & $\mathrm{C}_{9} \mathrm{H}_{8} \mathrm{O}_{4}$ & 180.16 & $252\left[\mathrm{C}_{12} \mathrm{H}_{16} \mathrm{O}_{4} \mathrm{Si}^{+}\right.$ & $209\left[\mathrm{C}_{10} \mathrm{H}_{13} \mathrm{O}_{3} \mathrm{Si}^{+}\right.$ & $149\left[\mathrm{C}_{8} \mathrm{H}_{5} \mathrm{O}_{3}\right]^{+}$ \\
IBP & $15687-27-1$ & $\mathrm{C}_{13} \mathrm{H}_{18} \mathrm{O}_{2}$ & 206.29 & $278\left[\mathrm{C}_{15} \mathrm{H}_{26} \mathrm{O}_{2} \mathrm{Si}^{+}\right.$ & $160\left[\mathrm{C}_{12} \mathrm{H}_{16}\right]^{+}$ & $263\left[\mathrm{C}_{15} \mathrm{H}_{18} \mathrm{O}_{2} \mathrm{Si}^{+}\right.$ \\
NAP & $22204-53-1$ & $\mathrm{C}_{14} \mathrm{H}_{14} \mathrm{O}_{3}$ & 230.26 & $302\left[\mathrm{C}_{17} \mathrm{H}_{22} \mathrm{O}_{3} \mathrm{Si}\right]^{+}$ & $185\left[\mathrm{C}_{13} \mathrm{H}_{13} \mathrm{O}\right]^{+}$ & $243\left[\mathrm{C}_{14} \mathrm{H}_{12} \mathrm{O}_{3}\right]^{+}$ \\
KPF & $22071-15-4$ & $\mathrm{C}_{16} \mathrm{H}_{14} \mathrm{O}_{3}$ & 254.28 & $325\left[\mathrm{C}_{19} \mathrm{H}_{22} \mathrm{O}_{3} \mathrm{Si}\right]^{+}$ & $282\left[\mathrm{C}_{15} \mathrm{H}_{14} \mathrm{O}_{3} \mathrm{Si}\right]^{+}$ & $295\left[\mathrm{C}_{17} \mathrm{H}_{15} \mathrm{O}_{3} \mathrm{Si}^{+}\right.$ \\
\hline
\end{tabular}

a Abbreviations: acetylsalicylic acid (ASA), ibuprofen (IBP), naproxen (NAP), ketoprofen (KPF); ${ }^{\text {b }}$ target and qualifier ions of the trimethylsilyl derivates.

The anthracene solution $\left(1 \mathrm{mg} \mathrm{mL}^{-1}\right)$ was prepared in ethanol, and by further dilution the working solution was obtained. $\mathrm{NaOH} 1 \mathrm{M}, \mathrm{HCl} 1 \mathrm{M}$, and $\mathrm{CH}_{3} \mathrm{COOH} 1 \mathrm{M}$ was used to adjust the $\mathrm{pH}$ of the blank, and real samples were prepared with ultrapure water (resistivity $18.2 \mathrm{M} \Omega \mathrm{cm}^{-1}$ ) and obtained by means of a Milli-Q purification system (Millipore, Bradford, MA, USA).

\subsection{Sample Preparation}

\subsubsection{Preparation of Simulated Urine Samples}

For simulating a urine sample, an aqueous solution containing the most present components was prepared as follows: urea $14 \mathrm{~g} \mathrm{~L}^{-1}$, creatinine $0.4 \mathrm{~g} \mathrm{~L}^{-1}$, uric acid $0.05 \mathrm{~g} \mathrm{~L}^{-1}$, glucose $0.06 \mathrm{~g} \mathrm{~L}^{-1}$, mono potassium phosphate $0.2 \mathrm{~g} \mathrm{~L}^{-1}$, and sodium chloride $13 \mathrm{~g} \mathrm{~L}^{-1}$.

\subsubsection{Preparation of Animal Urine Samples}

Animal urine samples were provided by small farm owners near Campobasso (Molise, Italy). Each sample was filtered through a $0.45 \mu \mathrm{m}$ pore size cellulose acetate filter and buffered at $\mathrm{pH} 5$ with few drops of acetic acid, with the addition of a few $\mu \mathrm{L}$ of $\mathrm{NaOH} 1 \mathrm{M}$. Before performing the extraction and derivatization procedures, the animal urine samples were subjected to enzymatic hydrolysis. With total of $9 \mathrm{~mL}$ of sample and $100 \mu \mathrm{L}$ of $\beta$-glucuronidase/arylsulfatase [45], the IS (5 $\mu \mathrm{L}$ of anthracene, $60 \mathrm{ng}$ $\mu \mathrm{L}^{-1}$ ) were incubated overnight at $37^{\circ} \mathrm{C}$.

\subsubsection{USVA-DLLME and Derivatization Procedure}

The extraction procedure was performed as follows: the mixture of dispersive ( $1 \mathrm{~mL}$ of acetone) and extraction ( $250 \mu \mathrm{L}$ of $\mathrm{CH}_{2} \mathrm{Cl}_{2}$ ) solvent was injected above the sample level of the solution previously kept at room temperature at $\mathrm{pH} 3$ with a few $\mu \mathrm{L}$ of $\mathrm{HCl}$ [46]. The solution was subjected to vortex for $1 \mathrm{~min}$ and ultrasounds for $2 \mathrm{~min}$ : This occurrence was repeated three times, followed by centrifugation for $10 \mathrm{~min}$ at $4000 \mathrm{rpm}$ at room temperature. The organic phase was withdrawn with a micro-syringe and placed in a vial with the addition of a few grains of anhydrous sodium sulphate. A total of $50 \mu \mathrm{L}$ of BSTFA + TMCS $(99+1, \mathrm{v}+\mathrm{v})$ were added [47] and the vial was closed and heated up to $50{ }^{\circ} \mathrm{C}$ for $30 \mathrm{~min}$. Afterwards, the vial was cooled at room temperature and the organic phase was concentrated to a final volume of $20-50 \mu \mathrm{L}$ under a slight nitrogen flow and $1 \mu \mathrm{L}$ were analyzed in GC-IT-MS. 


\subsection{GC-IT-MS Apparatus}

Analysis and data acquisition were performed using a gas chromatograph Finnigan Trace GC Ultra, equipped with an ion trap mass-spectrometry detector Polaris $Q$ (Thermo Fisher Scientific, Waltham, MA, USA), a programmed temperature vaporizer (PTV) injector, and a PC with a chromatography station Xcalibur 1.2.4 (Thermo Fisher Scientific).

A fused-silica capillary column with a chemically bonded phase (SE-54, 5\% phenyl-95\% dimethylpolysiloxane) was prepared in our laboratory [48-50] with the following characteristics: $30 \mathrm{~m} \times 250 \mu \mathrm{m}$ i.d.; $\mathrm{N}$ (theoretical plate number) 132,000 for $n$-dodecane at $90^{\circ} \mathrm{C}$; $\mathrm{K}^{\prime}$, capacity factor, 7.0; $\mathrm{d}_{\mathrm{f}}$, (film thickness) $0.246 \mu \mathrm{m} ; \mathrm{u}_{\mathrm{opt}}$ (optimum linear velocity of carrier gas, hydrogen) $39.5 \mathrm{~cm} \mathrm{~s}^{-1}$; utilization of theoretical efficiency (UTE) 95\%. A $1 \mu \mathrm{L}$ sample was injected into the PTV injector in the splitless mode. A total of $10 \mathrm{~s}$ after, the injection the vaporizer was heated from $110^{\circ} \mathrm{C}$ to $290^{\circ} \mathrm{C}$ at $800{ }^{\circ} \mathrm{C} \mathrm{min}{ }^{-1}$; the splitter valve was opened after $120 \mathrm{~s}$ (split ratio 1:50). The transfer line and ion source were held at $270{ }^{\circ} \mathrm{C}$ and $250^{\circ} \mathrm{C}$, respectively. Helium (IP 5.5) was used as a carrier gas at a flow rate of $10 \mathrm{~mL} \mathrm{~min}^{-1}$. The oven temperature program was as follows: $100^{\circ} \mathrm{C}$ for $60 \mathrm{~s}, 10^{\circ} \mathrm{C} \mathrm{min}^{-1}$ up to $290^{\circ} \mathrm{C}$, and held for $120 \mathrm{~s}$. The IT/MS was operated in the electron ionization mode $(70 \mathrm{eV})$, and the analytes were qualitatively identified in the full-scan mode $(\mathrm{m} / \mathrm{z} 100-500)$ and quantified in the selected ion monitoring (SIM) mode (Table 1). The quantitative analysis was performed by calibration graphs of ratio Area $_{(\mathrm{NSAID})} / \mathrm{Area}_{(\mathrm{IS})}$ plotted versus each NSAID concentration $\left(\mathrm{ng} \mathrm{mL}^{-1}\right)$. All the samples were determined in triplicate.

\section{Results and Discussion}

For USVA-DLLME extraction of the four investigated NSAIDs from animal urine samples, several parameters that control the optimal extraction performance were investigated and optimized using the one variable at a time method. It should be highlighted that the entire analytical methodology has been studied by means of simulated urine samples, prepared according to what reported in Section 2.2.1 and after applied to real urine samples. Simultaneously, the use of $\beta$-glucuronidase was welcome because it increased the IBP detection [33].

\subsection{Parameter Optimization}

The parameter optimization was addressed to find out the best analytical conditions for achieving high recoveries and accurate and precise determinations of the NSAIDs in animal urine samples. In this way, extraction solvent and volume, sample $\mathrm{pH}$, and $\mathrm{NaCl}$ effect were deeply investigated.

First, the study dedicated its attention on the choice of organic extraction solvent. This issue plays a key role in the extraction efficiency. Chlorinated solvents are generally used because they show characteristics (higher density than water, low solubility in water) appropriate to obtaining high extraction efficiency and worthy gas chromatographic performance. Following these considerations, our attention was focused to five solvents: dichloromethane $\left(\mathrm{CH}_{2} \mathrm{Cl}_{2} ; \mathrm{d}=1.3255\right.$ $\left.\mathrm{g} \mathrm{mL}{ }^{-1}\right)$, chloroform $\left(\mathrm{CHCl}_{3} ; \mathrm{d}=1.4788 \mathrm{~g} \mathrm{~mL}^{-1}\right)$, carbon tetrachloride $\left(\mathrm{CCl}_{4} ; \mathrm{d}=1.5940 \mathrm{~g} \mathrm{~mL}^{-1}\right)$, 1,2-dichloroethane $\left(\mathrm{C}_{2} \mathrm{H}_{4} \mathrm{Cl}_{2} ; \mathrm{d}=1.2454 \mathrm{~g} \mathrm{~mL}^{-1}\right)$, and 1,1,2,2-tetrachloroethane $\left(\mathrm{C}_{2} \mathrm{H}_{2} \mathrm{Cl}_{4} ; 1.5953 \mathrm{~g}\right.$ $\mathrm{mL}^{-1}$ ). Table 2 reports the results of the performance of a $300 \mu \mathrm{L}$ volume of each solvent on simulated urine samples spiked with $20 \mathrm{ng} \mathrm{mL}^{-1}$ of each NSAID: Dichloromethane shows the best recoveries, ranging between $94.6 \%$ and $98.5 \%$ for IBP, NAP, and KPF, respectively, and $82.5 \%$ for ASA with a relative standard deviation (RSD, \%) below 3.0. The recoveries are calculated as the accuracy (IS added before the extraction) [51].

The extraction recovery, defined as the percentage of the total analyte $\left(\mathrm{n}_{0}\right)$, that was extracted to the sediment phase $\left(\mathrm{n}_{\text {sed }}\right)$ has been determined according to the formula reported in a previous paper [36]. Over the extraction solvent choice, another quite important parameter is its volume, used to achieve the highest recoveries. The strength of the DLLME regards an extraction solvent volume as low as possible for obtaining good performance. Leong and Huang [39] highlighted that an extraction 
solvent volume leads to a change in the sediment phase volume and therefore in the enrichment factors (EFs). For these reasons, the effect of different dichloromethane volumes $(200,250,300 \mu \mathrm{L})$ were investigated (Table 3): a volume of $250 \mu \mathrm{L}$ is sufficient to obtain good recoveries for all the NSAIDs, i.e., $94.2 \%$ for ASA, 100.1 for IBP, 99.8 for NAP, and 101.2 for KPF with RSDs $\leq 3.1$.

Table 2. Effect of different extraction solvents on the NSAID recovery accuracy (\%). The conditions were as follows: $9 \mathrm{~mL}$ of simulated urine samples spiked with NSAIDs ( $20 \mathrm{ng} \mathrm{mL}{ }^{-1}$ of each), $1 \mathrm{~mL}$ of acetone, $300 \mu \mathrm{L}$ of extraction solvent, and $5 \mu \mathrm{L}$ of anthracene (I.S.; $60 \mathrm{ng} \mu \mathrm{L}^{-1}$ ). In brackets are reported the relative standard deviations (RSDs, \%); each analysis was in triplicate.

\begin{tabular}{cccccc}
\hline Compound & \multicolumn{5}{c}{ Accuracy (\%) } \\
\hline & $\mathbf{C H}_{\mathbf{2}} \mathbf{C l}_{\mathbf{2}}$ & $\mathbf{C H C l}_{\mathbf{3}}$ & $\mathbf{C C l}_{\mathbf{4}}$ & $\mathbf{C H}_{\mathbf{2}} \mathbf{C l C H} \mathbf{2} \mathbf{l}$ & $\mathbf{C H C l}_{\mathbf{2}} \mathbf{C H C l}_{\mathbf{2}}$ \\
\hline ASA & $82.5(2.5)$ & $79.2(3.2)$ & $74.1(2.7)$ & $76.1(2.1)$ & $74.2(3.0)$ \\
$\mathrm{IBP}$ & $94.6(3.0)$ & $81.7(2.6)$ & $82.3(3.0)$ & $83.2(2.7)$ & $85.2(2.9)$ \\
NAP & $96.8(2.9)$ & $83.4(3.1)$ & $84.5(3.1)$ & $85.4(3.0)$ & $86.3(3.1)$ \\
KPF & $98.5(2.8)$ & $85.2(3.0)$ & $86.5(2.9)$ & $89.1(2.9)$ & $86.2(2.9)$ \\
\hline
\end{tabular}

Table 3. Effect of different volumes of $\mathrm{CH}_{2} \mathrm{Cl}_{2}$ on the NSAID recoveries (\%). The conditions were as follows: $9 \mathrm{~mL}$ of simulated urine samples spiked with NSAIDs (20 $\mathrm{ng} \mathrm{mL}^{-1}$ of each), $1 \mathrm{~mL}$ of acetone, different volumes of $\mathrm{CH}_{2} \mathrm{Cl}_{2}$ as extraction solvent, and $5 \mu \mathrm{L}$ of IS $\left(60 \mathrm{ng} \mu \mathrm{L}^{-1}\right)$. In brackets are reported the RSDs (\%); each analysis was in triplicate.

\begin{tabular}{cccc}
\hline Compound & \multicolumn{3}{c}{ Recovery (\%) } \\
\hline & $\mathbf{2 0 0} \boldsymbol{\mu} \mathrm{L}$ & $\mathbf{2 5 0} \boldsymbol{\mu L}$ & $\mathbf{3 0 0} \boldsymbol{\mu L}$ \\
\hline ASA & $82.3(3.1)$ & $94.2(2.8)$ & $82.5(2.5)$ \\
IBP & $95.2(2.7)$ & $100.1(3.1)$ & $94.6(3.0)$ \\
NAP & $96.8(2.9)$ & $99.8(2.5)$ & $96.8(2.9)$ \\
KPF & $95.1(3.2)$ & $101.2(3.0)$ & $98.5(2.8)$ \\
\hline
\end{tabular}

Another parameter influencing the extraction is the $\mathrm{pH}$ of the solution. In fact, it should be remembered that NSAIDs are weak acids. Particularly, ASA shows a pKa of 3.5 [52], IBP of 5.3 [53], NAP of 4.14, and KPF of 4.45 [54]. Solutions of simulated urine samples at different $\mathrm{pH}$ were tested for studying the best acidic conditions. Table 4 evidences that the best recoveries and RSDs are obtained at $\mathrm{pH}$ 3: in fact, they range between 93.5 and 100.1\% and between 3.4 and $4 \%$, respectively.

Table 4. The effect of $\mathrm{pH}$ on the NSAID recoveries (\%). The conditions were as follows: $9 \mathrm{~mL}$ of simulated urine samples spiked with NSAIDs (20 ng mL -1 of each), $1 \mathrm{~mL}$ of acetone, $250 \mu \mathrm{L}$ of $\mathrm{CH}_{2} \mathrm{Cl}_{2}$, and $5 \mu \mathrm{L}$ of IS (60 ng $\left.\mu \mathrm{L}^{-1}\right)$. In brackets are reported the RSDs (\%); each analysis was in triplicate.

\begin{tabular}{cccccc}
\hline Compound & \multicolumn{5}{c}{ Recovery (\%) } \\
\hline \multicolumn{7}{c}{ pH 2 } & pH 3 & pH 4 & pH 5 & pH 6 \\
\hline ASA & $94.1(5.6)$ & $93.5(3.5)$ & $86.1(4.0)$ & $82.0(4.2)$ & $70.0(4.3)$ \\
IBP & $100.2(3.3)$ & $99.7(3.4)$ & $97.2(3.9)$ & $92.5(4.1)$ & $82.2(4.1)$ \\
NAP & $99.8(3.8)$ & $100.1(3.9)$ & $96.8(4.1)$ & $91.0(4.0)$ & $81.5(4.0)$ \\
KPF & $101.0(3.7)$ & $99.7(4.0)$ & $97.2(4.2)$ & $90.2(3.9)$ & $84.7(4.3)$ \\
\hline
\end{tabular}


Finally, the effect of different $\mathrm{NaCl}$ quantities on the NSAID recoveries was evaluated. Table 5 shows that the salt decreased the NSAID solubility (salting out) below and above $13 \mathrm{~g} \mathrm{~L}^{-1}$ concentration. Further, the decision to perform the whole study at $\mathrm{NaCl}$ concentration of $13 \mathrm{~g} \mathrm{~L}^{-1}$ was essentially due to two considerations: (1) this concentration was the average of those reported in the real urine samples, which was between 10 and $16 \mathrm{~g} \mathrm{~L}^{-1}$ of $\mathrm{NaCl}$ [55]; (2) the percentage NSAID recoveries obtained and reported in Table 5 were very similar to each other for $\mathrm{NaCl}$ concentrations between 10 and $15 \mathrm{~g} \mathrm{~L}^{-1}$.

Finally, it should be highlighted that two other interesting parameters, such as vortex time and ultrasonication time, were extensively studied in previous papers by this group [41-44].

Table 5. Effect of different $\mathrm{NaCl}$ amounts on the NSAID recoveries (\%). The conditions were as follows: $9 \mathrm{~mL}$ of simulated urine samples spiked with NSAIDs (20 $\mathrm{ng} \mathrm{mL}^{-1}$ of each), $\mathrm{pH} 3,1 \mathrm{~mL}$ of acetone, $250 \mu \mathrm{L}$ of $\mathrm{CH}_{2} \mathrm{Cl}_{2}$, and $5 \mu \mathrm{L}$ of IS $\left(60 \mathrm{ng} \mu \mathrm{L}^{-1}\right)$. In brackets are reported the RSDs (\%); each analysis was in triplicate.

\begin{tabular}{|c|c|c|c|c|c|c|}
\hline \multirow[t]{2}{*}{ Compound } & \multicolumn{6}{|c|}{ Recovery (\%) } \\
\hline & $5 \mathrm{~g} \mathrm{~L}^{-1}$ & $10 \mathrm{~g} \mathrm{~L}^{-1}$ & $13 \mathrm{~g} \mathrm{~L}^{-1}$ & $15 \mathrm{~g} \mathrm{~L}^{-1}$ & $20 \mathrm{~g} \mathrm{~L}^{-1}$ & $25 \mathrm{~g} \mathrm{~L}^{-1}$ \\
\hline ASA & $80.1(4.0)$ & 89.5 (3.9) & $93.2(3.6)$ & $93.8(3.5)$ & $85.2(4.1)$ & $83.5(3.9)$ \\
\hline IBP & $92.5(3.7)$ & $97.2(3.5)$ & $99.4(3.5)$ & 99.5 (3.7) & $92.5(3.8)$ & $90.1(4.0)$ \\
\hline NAP & $94.2(4.1)$ & $97.1(4.2)$ & $100.6(3.9)$ & $101.0(4.0)$ & $91.6(4.2)$ & $89.2(4.1)$ \\
\hline $\mathrm{KPF}$ & $95.2(3.9)$ & $97.5(4.0)$ & $99.8(3.9)$ & $100.1(7.8)$ & $93.2(4.0)$ & $90.2(3.8)$ \\
\hline
\end{tabular}

\subsection{GC-IT-MS Method Validation}

Using optimized parameters, all the analytical data were investigated. Table 6 shows the correlation coefficients $\left(\mathrm{R}^{2}\right)$ in the range 1-100 $\mathrm{g} \mathrm{L} \mathrm{L}^{-1}$, along with the limits of detection (LODs) and limits of quantification (LOQs), repeatability (as intra-day precision) and reproducibility (as inter-day precision), and EFs of each NSAID considered. LODs and LOQs were determined according to Knoll's definition [56,57], i.e., an analyte concentration that produces a chromatographic peak equal to three times (LOD) and seven times (LOQ) the standard deviation of the baseline noise. All the compounds show a good linearity in the investigated range $(\geq 0.995)$ and LODs and LOQs between $0.1-0.2 \mu \mathrm{g} \mathrm{L}-1$ and $4.1-4.7 \mu \mathrm{g} \mathrm{L}{ }^{-1}$, respectively, with high intra- and inter-day precision $(\leq 3.8$ and $\leq 4.5$, respectively). The EFs, defined as the ratio between the analyte concentration in the sediment phase $\left(\mathrm{C}_{\text {sed }}\right)$ and the initial analyte concentration $\left(\mathrm{C}_{0}\right)$ in the sample $\left(\mathrm{EF}=\mathrm{C}_{\text {sed }} / \mathrm{C}_{0}\right)$ [35], were also studied, ranging between $350-450$.

Table 6. Correlation coefficients $\left(\mathrm{R}^{2}\right)$ calculated in the range $1-100 \mu \mathrm{g} \mathrm{L}^{-1}$, limit of detection (LOD; $\mu \mathrm{g} \mathrm{L}^{-1}$ ) and limit of quantification (LOQ; $\mu \mathrm{g} \mathrm{L}^{-1}$ ) and inter- and intra-day precision (expressed as RSD, \%) of each NSAID determined by GC-IT-MS.

\begin{tabular}{ccccccc}
\hline Compound & $\mathbf{R}^{\mathbf{2}}$ & LOD & LOQ & Intra-day & Inter-day & EF \\
\hline ASA & 0.9950 & 0.2 & 4.1 & 3.8 & 4.5 & 350 \\
IBP & 0.9972 & 0.1 & 4.7 & 3.2 & 4.0 & 450 \\
NAP & 0.9987 & 0.1 & 4.7 & 3.5 & 4.3 & 385 \\
KPF & 0.9981 & 0.1 & 4.5 & 3.3 & 4.2 & 412 \\
\hline
\end{tabular}

Finally, for a complete analytical methodology evaluation, the recoveries have been studied in the investigated matrices, i.e., animal urine, at two different spiked NSAID concentrations $\left(20 \mathrm{ng} \mathrm{mL}^{-1}\right.$ and $50 \mathrm{ng} \mathrm{mL}^{-1}$ ). Table 7 shows these data: recoveries in animal urine samples between 93.8 and 102 with RSDs $\leq 3.2$. 
Table 7. Average NSAID recoveries (\%) obtained at different spiking concentrations on real urine samples. In brackets are reported the RSDs (\%); each analysis was in triplicate.

\begin{tabular}{|c|c|c|}
\hline \multirow[t]{3}{*}{ Compound } & \multicolumn{2}{|c|}{ Recovery (\%) } \\
\hline & \multicolumn{2}{|c|}{ Animal Urine ${ }^{a}$} \\
\hline & $20 \mathrm{ng} \mathrm{mL}^{-1}$ & $50 \mathrm{ng} \mathrm{mL}^{-1}$ \\
\hline ASA & $93.8(3.2)$ & $94.3(2.9)$ \\
\hline IBP & $99.8(3.0)$ & $100.2(3.0)$ \\
\hline NAP & $101.0(3.2)$ & $102.0(3.1)$ \\
\hline KPF & $100.2(2.9)$ & $99.8(3.2)$ \\
\hline
\end{tabular}

Finally, Table 8 shows a comparison among different methods present in literature [58-63] for analyzing NSAIDs. The extraction methods were different: three papers were based on hollow-fiber liquid microextraction [59,60,62], whereas two papers were on rotating disk sorptive [63] and liquid-liquid extraction [61]. According to the analytical techniques, three studies used HPLC with ultraviolet (UV) $[58,61,63]$ and one the diode array detection (DAD) [59], one used the ultra-performance liquid chromatography coupled with tandem mass spectrometry (UPLC-MS/MS) [62], and one used GC equipped with a flame ionization detector (FID) [60]. Looking at the comparison among the different studies with parameters developed in this study, the main advantages regard LODs and LOQs, recoveries, and RSDs, whereas EFs are good except those reported by Payan et al. [59]. On the other hand, the whole procedure can be routinely applied and does not require particular technology, such as the use of rotating disks or hollow fiber. 
Table 8. Linear range (LR, $\left.\mu \mathrm{g} \mathrm{mL}{ }^{-1}\right)$, volume of extraction solvent (Ex. Solv., $\left.\mu \mathrm{L}\right)$, extraction time (Ex. Tm., min), enrichment factor (EF), limit of detection (LOD, $\mu \mathrm{g} \mathrm{L}^{-1}$ ), limit of quantification (LOQ $\mu \mathrm{g} \mathrm{L}^{-1}$ ), recovery (\%), and relative standard deviation (RSD, \%) of each NSAID investigated in this study and relative comparison with similar studies present in literature.

\begin{tabular}{|c|c|c|c|c|c|c|c|c|c|c|c|}
\hline Method & Matrix & Analyte & LR & Ex. Solv. & Ex. Tm. & EF & LOD & LOQ & Recovery & RSD & Ref. \\
\hline LLE-HPLC-UV $^{1}$ & human plasma & KPF, NAP, FPC ${ }^{7}$, IBP, $^{-1 C^{7}}$ & $100-100,000$ & 600 & n.r. ${ }^{8}$ & n.r. ${ }^{8}$ & $11.5-75$ & n.r. ${ }^{8}$ & $97.1-146.6$ & $<10.1$ & [58] \\
\hline HF-LPME-HPLC-DAD (or FLD) ${ }^{2}$ & human urine & $\mathrm{DIC}^{7}, \mathrm{ASA}, \mathrm{IBP}$ & $41-10,000$ & 50 & 15 & 70-1010 & $12.3-52.9$ & n.r. ${ }^{8}$ & $82.3-99$ & $<1.8$ & [59] \\
\hline HFLM-SPME-GC-FID ${ }^{3}$ & human urine & IBP, NAP, DIC ${ }^{7}$ & $0.08-400$ & 6 & 80 & $46.5-60.5$ & $0.03-0.07$ & $0.08-0.1$ & $80.2-98.5$ & $<12.1$ & [60] \\
\hline SPE-SUPRASF-HPLC-UV 4 & human urine, water & $\mathrm{DIC}^{7}, \mathrm{MFA}^{7}$ & $10-300$ & 1500 & 25 & $431-489$ & $0.4-7.0$ & n.r. ${ }^{8}$ & $90.4-103.8$ & $<6.2$ & [61] \\
\hline HF-LPME-UPLC-(MS/MS) ${ }^{5}$ & $\begin{array}{l}\text { water, juice, soda, } \\
\text { energy drink }\end{array}$ & ASA, IBP, NAP, DIC ${ }^{7}$ & $1-5000$ & 15 & 30 & 195-350 & $0.5-1.25$ & $2.0-5.0$ & $87.9-115.2$ & $<12.0$ & [62] \\
\hline RDSE-HPLC-UV ${ }^{6}$ & human urine & $\mathrm{DIC}^{7}$, IBP, KPF, NAP & $200-2000$ & 200 & 20 & $15-18$ & $21.7-44.0$ & $72.4-146.6$ & $100-110$ & $<12.0$ & [63] \\
\hline USVA-DLLME-GC-IT-MS & animal urine & ASA, IBP, NAP, KPF & $1-100$ & 250 & 19 & $300-450$ & $0.1-0.2$ & $4.1-4.7$ & 94.1-101 & $<4.1$ & This study \\
\hline
\end{tabular}

${ }^{1}$ Liquid-liquid extraction-high performance liquid chromatography-ultraviolet (LLE-HPLC-UV) detector; ${ }^{2}$ hollow-fiber liquid-phase microextraction-high performance liquid chromatography-diode-array detection; ${ }^{3}$ hollow-fiber liquid membrane-protected solid-phase microextraction-gas chromatography flame ionization detector; ${ }^{4}$ solid phase extraction combined with supramolecular solvent-high performance liquid chromatography-UV; ${ }^{5}$ hollow-fiber liquid-phase microextraction-ultra performance liquid chromatography-tandem mass spectrometry; ${ }^{6}$ rotating disk sorptive extraction HPLC-UV; ${ }^{7}$ diclofenac (DIC), fenoprofen (FPC), mefenamic acid (MFA); ${ }^{8}$ not reported. 


\subsection{Application to Real Animal Urine Samples}

Using the entire analytical USVA-DLLME-GC-IT-MS protocol previously developed (briefly resuming: $9 \mathrm{~mL}$ of simulated urine sample solution at $\mathrm{pH} 3$ containing $5 \mu \mathrm{L}$ of I.S., $60 \mathrm{ng} \mathrm{mL}^{-1}$, addition of $1 \mathrm{~mL}$ of acetone and of $250 \mu \mathrm{L}$ dichloromethane as extraction solvent, three times of $1 \mathrm{~min}$ vortex and $2 \mathrm{~min}$ ultrasounds, centrifugation for $10 \mathrm{~min}$ at $4000 \mathrm{rpm}, 1 \mu \mathrm{L}$ injection into GC-IT-MS), some animal urine samples have been analyzed, particularly three animal urine samples, i.e., two from goats and one from a sheep. All the subjects were healthy. No residues (i.e., levels below the LODs) were found in all the samples. The analysis allows us to investigate the presence of such compounds at trace levels in these matrices, but it does not furnish evidence as to whether there was a previous assumption of such molecules. As an example are shown in Figure 1, the gas chromatograms in SIM mode of a simulated sample of urine (a) and one of goat urine sample (b) both additions with $30 \mathrm{ng} \mathrm{mL}-1$ of each NSAID. The peaks are well-solved and the determinations are precise and accurate.
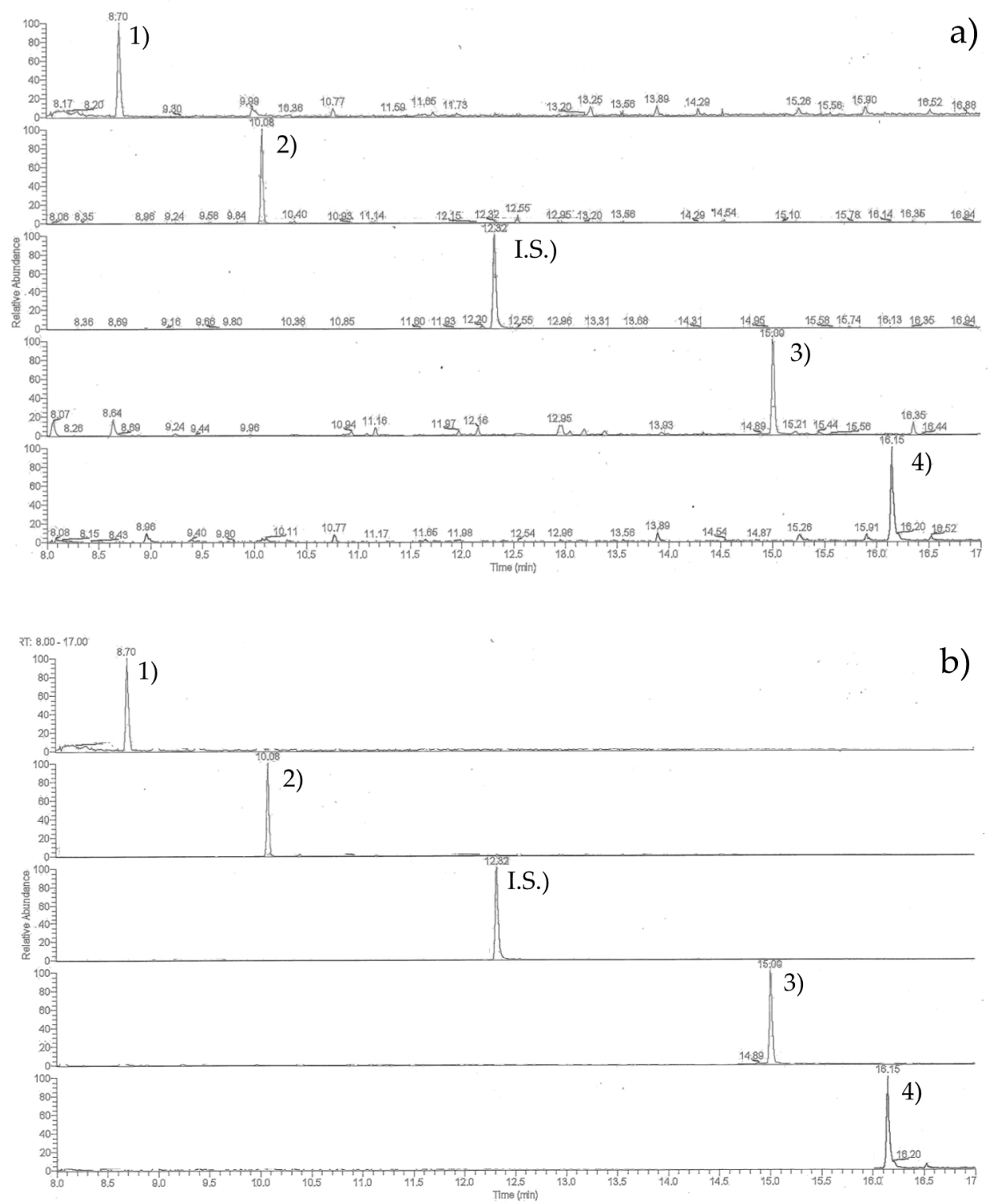

Figure 1. Gas chromatography/ion trap-mass spectrometry (GC-IT-MS) chromatograms in SIM mode of (a) simulated urine and (b) goat urine samples, both spiked with $30 \mathrm{ng} \mathrm{mL}^{-1}$ of each NSAID. For experimental conditions, see text. Peak list: 1 . acetylsalicylic acid; 2 . ibuprofen; internal standard (IS); 3. naproxen; 4. ketoprofen. 


\section{Conclusions}

This paper highlights an affordable method for analyzing NSAIDs in animal urine samples. The method used for the animal urine samples in this study can also be applied to human urine samples, as a lead on to the discussion about athletes. In fact, athletes often make excessive use of anti-inflammatories in order to compete, even in less than optimal physical conditions. Many athletes take NSAIDs to compete or even simply train, even in the presence of pain, joint inflammation, trauma etc. Incorrect use of these drugs can lead to serious damage to health. Further, with regards to "premedication" in the sports field, it should be highlighted that the NSAIDs are not among the substances prohibited by the anti-doping measures and are therefore only drugs at risk of easy inappropriate abuse. Equine doping can also be defined as "the use of any exogenous agent (pharmacological, endocrinological, hematological, etc.) or clinical manipulation, which, in the absence of suitable and necessary therapeutic indications, is aimed to improve performance, outside the adjustments induced by training. In this view, this paper shows a simple, rapid, and sensitive method for determining four NSAIDs in animal urine samples. The very low LODs and LOQs and the high precision reached by means of a modified DLLME method coupled with GC-IT-MS allow us to apply the entire procedure to routine screening and monitoring of such compounds in doping cases or other similar situations.

Author Contributions: Conceptualization, M.V.R.; methodology, M.V.R. and P.A.; validation, I.N. and S.P.; formal analysis, S.P.; investigation, I.N.; resources, M.V.R.; data curation, M.V.R. and P.A.; writing-original draft preparation, P.A.; writing-review and editing, M.V.R. and P.A.; supervision, M.V.R.; project administration, M.V.R. All authors have read and agreed to the published version of the manuscript.

Funding: This research received no external funding.

Acknowledgments: The authors would like to thank Alessandro Ubaldi for his helpful suggestions in the data interpretation.

Conflicts of Interest: The authors declare no conflict of interest.

\section{References}

1. Baigent, C.; Bhala, N.; Emberson, J.; Merhi, A.; Abramson, S.; Arber, N.; Baron, J.A.; Bombardier, C.; Cannon, C.; Farkouh, M.E.; et al. Vascular and upper gastrointestinal effects of non-steroidal anti-inflammatory drugs: Meta-analyses of individual participant data from randomised trials. Lancet 2013, 382, 769-779.

2. Atkinson, T.J.; Fudin, J. Nonsteroidal antiinflammatory drugs for acute and chronic pain. Phys. Med. Rehabil. Clin. N. Am. 2020, 31, 219-231. [CrossRef]

3. Gunaydin, C.; Sirri Bilge, S. Effects of nonsteroidal anti-inflammatory drugs at the molecular level. Eurasian J. Med. 2018, 50, 116-121. [CrossRef] [PubMed]

4. Samad, T.A.; Sapirstein, A.; Woolf, C.J. Prostanoids and pain: Unraveling mechanisms and revealing therapeutic targets. Trends Mol. Med. 2002, 8, 390-396. [CrossRef]

5. Wasfi, I.A.; Boni, N.S.; Abdel Hadi, A.A.; ElGhazali, M.; Zorob, O.; Alkatheeri, N.A.; Barezaiq, I.M. Pharmacokinetics, metabolism and urinary detection time of flunixin after intravenous administration in camels. J. Vet. Pharmacol. Therap. 1998, 21, 203-208. [CrossRef] [PubMed]

6. Greisman, L.A.; Mackowiak, P.A. Fever: Beneficial and detrimental effects of antipyretics. Curr. Opin. Infect. Dis. 2002, 15, 241-245. [CrossRef]

7. Varas-Lorenzo, C.; Maguire, A.; Castellsague, J.; Perez-Gutthann, S. Quantitative assessment of the gastrointestinal and cardiovascular risk-benefit of celecoxib compared to individual NSAIDs at the population level. Pharmacoepidemiol. Drug Saf. 2007, 16, 366-376. [CrossRef]

8. Pountos, I.; Georgouli, T.; Calori, G.M.; Giannoudis, P.V. Do nonsteroidal anti-inflammatory drugs affect bone healing? A critical analysis. Sci. World J. 2012, 2012, 606404. [CrossRef]

9. Maniar, K.H.; Jones, I.A.; Gopalakrishna, R.; Vangsness, C.T. Lowering side effects of NSAID usage in osteoarthritis: Recent attempts at minimizing dosage. Expert Opin. Pharmacother. 2018, 19, 93-102. [CrossRef] 
10. Bjarnason, I.; Scarpignato, C.; Holmgren, E.; Olszewski, M.; Rainsford, K.D.; Lanas, A. Mechanisms of damage to the gastrointestinal tract from nonsteroidal anti-inflammatory drugs. Gastroenterology 2018, 154, 500-514. [CrossRef]

11. Szeto, C.C.; Sugano, K.; Wang, J.G.; Fujimoto, K.; Whittle, S.; Modi, G.K.; Chen, C.H.; Park, J.B.; Tam, L.S.; Vareesangthip, K.; et al. Non-steroidal anti-inflammatory drug (NSAID) therapy in patients with hypertension, cardiovascular, renal or gastrointestinal comorbidities: Joint APAGE/APLAR/APSDE/APSH/APSN/PoA recommendations. Gut 2020, 69, 617-629. [CrossRef] [PubMed]

12. González, G.; Ventura, R.; Smith, A.K.; de la Torre, R.; Segura, J. Detection of non-steroidal anti-inflammatory drugs in equine plasma and urine by gas chromatography-mass spectrometry. J. Chromatogr. A 1996, 719, 251-264. [CrossRef]

13. Thevis, M.; Fußhöller, G.; Schänzer, W. Zeranol: Doping offence or mycotoxin? A case-related study. Drug Test Anal. 2011, 3, 777-783. [CrossRef] [PubMed]

14. Conaghan, P.G. A turbulent decade for NSAIDs: Update on current concepts of classification, epidemiology, comparative efficacy, and toxicity. Rheumatol. Int. 2012, 32, 1491-1502. [CrossRef] [PubMed]

15. Jaussaud, P.; Guieu, D.; Courtot, D.; Barbier, B.; Bonnaire, Y. Identification of a tolfenamic acid metabolite in the horse by gas chromatography-mass spectrometry. J. Chromatogr. 1992, 3, 136-140. [CrossRef]

16. Cortout, D.; Jaussaud, P. Anti-inflammatoires et contrôle antidopage chez le cheval. Sci. Sports 1993, 8, 53-54. [CrossRef]

17. Tsitsimpikou, C.; Spyridaki, M.H.E.; Georgoulakis, I.; Kouretas, D.; Konstantinidou, M.; Georgokopulous, C.G. Elimination profiles of flurbiprofen and its metabolites in equine urine for doping analysis. Talanta 2001, 55, 1173-1180. [CrossRef]

18. Fédération Équestre Internationale (FEI). Equine Prohibited Substances Database. Available online: http://prohibitedsubstancesdatabase.feicleansport.org/search/ (accessed on 23 May 2020).

19. International Federation of Horseracing Authorities (IFHA). International Agreement: Art. 6A-Prohibited Substances. Available online: https://www.ifhaonline.org/default.asp?section=IABRW\&AREA=2\#article6a (accessed on 23 May 2020).

20. Maurer, H.H.; Tauvel, F.X.; Kraemer, T. Screening procedure for detection of non-steroidal anti-inflammatory drugs and their metabolites in urine as part of a systematic toxicological analysis procedure for acidic drugs and poisons by gas chromatography-mass spectrometry after extractive methylation. J. Anal. Toxicol. 2001, 25, 237-244.

21. Oliva, A.; De Giorgio, F.; Arena, V.; Fucci, N.; Pascali, V.L.; Navarra, P. Death due to anaphylactic shock secondary to intravenous self-injection of Toradol ${ }^{\circledR}$ : A case report and review of the literature. Clin. Toxicol. 2007, 45, 709-713. [CrossRef]

22. Albert, K.S.; Gernaat, C.M. Pharmacokinetics of ibuprofen. Am. J. Med. 1984, 77, 40-46. [CrossRef]

23. Soma, L.R.; Uboh, C.E.; Maylin, G.M. The use of phenylbutazone in the horse. J. Vet. Pharmacol. Therap. 2011, 35, 1-12. [CrossRef] [PubMed]

24. El Haj, B.M.; Al Ainri, A.M.; Hassan, M.H.; Bin Khadem, R.K.; Marzouq, M.S. The GC/MS analysis of some commonly used non-steriodal anti-inflammatory drugs (NSAIDs) in pharmaceutical dosage forms and in urine. Forensic Sci. Int. 1999, 105, 141-153. [CrossRef]

25. Kim, J.Y.; Kim, S.J.; Paeng, K.J.; Chung, B.C. Measurement of ketoprofen in horse urine using gas chromatography-mass spectrometry. J. Vet. Pharmacol. Ther. 2001, 24, 315-319. [CrossRef]

26. Wasfi, I.A.; Hussain, M.M.; Elghazali, M.; Alkatheeri, N.A.; Abdel Hadi, A.A. The disposition of diclofenac in camels after intravenous administration. Vet. J. 2003, 166, 277-283. [CrossRef]

27. Levreri, I.; Caruso, U.; Deiana, F.; Buoncompagni, A.; De Bernardi, B.; Marchese, N.; Melioli, G. The secretion of ibuprofen metabolites interferes with the capillary chromatography of urinary homovanillic acid and 4-hydroxy-3-methoxymandelic acid in neuroblastoma diagnosis. Clin. Chem. Lab. Med. 2005, 43, 173-177. [CrossRef]

28. Mareck, U.; Sigmund, G.; Opfermann, G.; Geyer, H.; Thevis, M.; Schänzer, W. Identification of the aromatase inhibitor letrozole in urine by gas chromatography/mass spectrometry. Rapid Commun. Mass Spectrom. 2005, 19, 3689-3693. [CrossRef]

29. Główka, F.K.; Karaźniewicz, M. High performance capillary electrophoresis method for determination of ibuprofen in human serum and urine. Anal. Chim. Acta 2005, 540, 95-102. [CrossRef] 
30. Azzouz, A.; Ballesteros, E. Gas chromatography-mass spectrometry determination of pharmacologically active substances in urine and blood samples by use of a continuous solid-phase extraction system and microwave-assisted derivatization. J. Chromatogr. B 2012, 891, 12-19. [CrossRef]

31. Yilmaz, B.; Erdem, A.F. Determination of ibuprofen in human plasma and urine by gas chromatography/mass spectrometry. J. AOAC Int. 2014, 97, 415-420. [CrossRef]

32. Waraksa, E.; Woźniak, M.K.; Kłodzińska, E.; Wrzesień, R.; Bobrowska-Korczak, B.; Namieśnik, J. A rapid and sensitive method for the quantitative analysis of ibuprofen and its metabolites in equine urine samples by gas chromatography with tandem mass spectrometry. J. Sep. Sci. 2018, 41, 3881-3891. [CrossRef]

33. Waraksa, E.; Woźniak, M.K.; Banaszkiewicz, L.; Kłodzińska, E.; Ozimek, M.; Wrzesień, R.; Bobrowska-Korczak, B.; Namieśnik, J. Quantification of unconjugated and total ibuprofen and its metabolites in equine urine samples by gas chromatography-tandem mass spectrometry: Application to the excretion study. Microchem. J. 2019, 150, 104129. [CrossRef]

34. Waraksa, E.; Wójtowicz-Zawadka, M.; Kwiatkowska, D.; Jarek, A.; Małkowska, A.; Wrzesien, R.; Namiesnika, J. Simultaneous determination of ibuprofen and its metabolites in complex equine urine matrices by GC-EI-MS in excretion study in view of doping control. J. Pharm. Biomed. Anal. 2018, 152, 279-288. [CrossRef] [PubMed]

35. Rezaee, M.; Assadi, Y.; Hosseini, M.R.M.; Aghaee, E.; Ahmadi, F.; Berijani, S. Determination of organic compounds in water using dispersive liquid-liquid microextraction. J. Chromatogr. A 2006, 1116, 1-9. [CrossRef]

36. Cinelli, G.; Avino, P.; Notardonato, I.; Centola, A.; Russo, M.V. Rapid analysis of six phthalate esters in wine by ultrasound-vortex-assisted dispersive liquid-liquid micro-extraction coupled with gas chromatography-flame ionization detector or gas chromatography-ion trap mass spectrometry. Anal. Chim. Acta 2013, 769, 72-78. [CrossRef] [PubMed]

37. Avino, P.; Notardonato, I.; Perugini, L.; Russo, M.V. New protocol based on high-volume sampling followed by DLLME-GC-IT/MS for determining PAHs at ultra-trace levels in surface water samples. Microchem. J. 2017, 133, 251-257. [CrossRef]

38. Notardonato, I.; Russo, M.V.; Vitali, M.; Protano, C.; Avino, P. Analytical method validation for determining organophosphorus pesticides in baby foods by a modified liquid-liquid microextraction method and gas chromatography-ion trap/mass spectrometry analysis. Food Anal. Methods 2019, 12, 41-50. [CrossRef]

39. Leong, M.I.; Huang, S.D. Determination of volatile organic compounds in water using ultrasound-assisted emulsification microextraction followed by gas chromatography. J. Sep. Sci. 2012, 35, 688-694. [CrossRef] [PubMed]

40. Russo, M.V.; Notardonato, I.; Avino, P.; Cinelli, G. Fast determination of phthalate ester residues in soft drinks and light alcoholic beverages by ultrasound/vortex assisted dispersive liquid-liquid microextraction followed by gas chromatography-ion trap mass spectrometry. RSC Adv. 2014, 4, 59655-59663. [CrossRef]

41. Russo, M.V.; Avino, P.; Notardonato, I. Fast analysis of phthalates in freeze-dried baby foods by ultrasound-vortex-assisted liquid-liquid microextraction coupled with gas chromatography-ion trap/mass spectrometry. J. Chromatogr. A 2016, 1474, 1-7. [CrossRef]

42. Russo, M.V.; Avino, P.; Perugini, L.; Notardonato, I. Fast analysis of nine PAHs in beer by ultrasound-vortex-assisted dispersive liquid-liquid micro-extraction coupled with gas chromatography-ion trap mass spectrometry. RSC Adv. 2016, 6, 13920-13927. [CrossRef]

43. Notardonato, I.; Salimei, E.; Russo, M.V.; Avino, P. Simultaneous determination of organophosphorus pesticides and phthalates in baby food samples by ultrasound-vortex-assisted liquid-liquid microextraction and GC-IT/MS. Anal. Bioanal. Chem. 2018, 410, 3285-3296. [CrossRef] [PubMed]

44. Notardonato, I.; Passarella, S.; Ianiri, G.; Di Fiore, C.; Russo, M.V.; Avino, P. Analytical method development and chemometric approach for evidencing presence of plasticizer residues in nectar honey samples. Int. J. Environ. Res. Public Health 2020, 17, 1692. [CrossRef] [PubMed]

45. Croes, K.; Goeyens, L.; Baeyens, W.; Van Loco, J.; Impens, S. Optimization and validation of a liquid chromatography tandem mass spectrometry $\left(\mathrm{LC} / \mathrm{MS}^{\mathrm{n}}\right)$ method for analysis of corticosteroids in bovine liver: Evaluation of Keyhole Limpet beta-glucuronidase/sulfatase enzyme extract. J. Chromatogr. $B$ 2009, 877, 635-644. [CrossRef] [PubMed]

46. Cinelli, G.; Avino, P.; Notardonato, I.; Russo, M.V. Ultrasound-vortex-assisted dispersive liquid-liquid microextraction coupled with gas chromatography with a nitrogen-phosphorus detector for simultaneous and rapid determination of organophosphorus pesticides and triazines in wine. Anal. Methods 2014, 6, 782-790. [CrossRef] 
47. Sebők, Á.; Vasanits-Zsigrai, A.; Palkó, G.; Záray, G.; Molnár-Perl, I. Identification and quantification of ibuprofen, naproxen, ketoprofen and diclofenac present in waste-waters, as their trimethylsilyl derivatives, by gas chromatography mass spectrometry. Talanta 2008, 76, 642-650. [CrossRef]

48. Russo, M.V.; Goretti, G.C.; Liberti, A. A fast procedure to immobilize polyethylene glycols in glass capillary columns. J. High Resolut. Chromatogr. 1985, 8, 535-538. [CrossRef]

49. Cartoni, G.P.; Castellani, L.; Goretti, G.; Russo, M.V.; Zacchei, P. Gas-liquid microcapillary columns precoated with graphitized carbon black. J. Chromatogr. 1991, 552, 197-204. [CrossRef]

50. Russo, M.V.; Goretti, G.; Soriero, A. Preparation and application of fused-silica capillary microcolumns (25-50 $\mu \mathrm{m}$ ID) in gas chromatography. Ann. Chim. 1996, 86, 115-124.

51. Matuszewski, B.K.; Constanzer, M.L.; Chavez-Eng, C.M. Strategies for the assessment of matrix effect in quantitative bioanalytical methods based on HPLC-MS/MS. Anal. Chem. 2003, 75, 3019-3030. [CrossRef]

52. Dressman, J.B.; Nair, A.; Abrahamsson, B.; Barends, D.M.; Groot, D.W.; Kopp, S.; Langguth, P.; Polli, J.E.; Shah, V.P.; Zimmer, M. Biowaiver monograph for immediate-release solid oral dosage forms: Acetylsalicylic acid. J. Pharm. Sci. 2012, 101, 2653-2667. [CrossRef]

53. Bushra, R.; Aslam, N. An overview of clinical pharmacology of ibuprofen. Oman Med. J. 2010, $25,155-161$. [CrossRef] [PubMed]

54. Sangster, J. LogKOW Database. A Databank of Evaluated Octanol-Water Partition Coefficients (Log P). Available online: http://logkow.cisti.nrc.ca/logkow/search.html (accessed on 23 May 2020).

55. Spek, J.W.; Bannink, A.; Gort, G.; Hendriks, W.H.; Dijkstra, J. Effect of sodium chloride intake on urine volume, urinary urea excretion, and milk urea concentration in lactating dairy cattle. J. Dairy Sci. 2012, 95, 7288-7298. [CrossRef] [PubMed]

56. Knoll, J.E. Estimation of the limit of detection in chromatography. J. Chromatogr. Sci. 1985, 23, 422-425. [CrossRef]

57. Russo, M.V.; Avino, P.; Cinelli, G.; Notardonato, I. Sampling of organophosphorus pesticides at trace levels in the atmosphere using XAD-2 adsorbent and analysis by gas chromatography coupled with nitrogen-phosphorus and ion-trap mass spectrometry detectors. Anal. Bioanal. Chem. 2012, 404, 1517-1527. [CrossRef] [PubMed]

58. Sun, Y.; Takaba, K.; Kido, H.; Nakashima, M.N.; Nakashima, K. Simultaneous determination of arylpropionic acidic non-steroidal anti-inflammatory drugs in pharmaceutical formulations and human plasma by HPLC with UV detection. J. Pharm. Biomed. Anal. 2003, 30, 1611-1619. [CrossRef]

59. Payán, M.R.; López, M.Á.B.; Fernández-Torres, R.; Bernal, J.L.P.; Mochón, M.C. HPLC determination of ibuprofen, diclofenac and salicylic acid using hollow fiber-based liquid phase microextraction (HF-LPME). Anal. Chim. Acta 2009, 653, 184-190. [CrossRef]

60. Sarafraz-Yazdia, A.; Amiri, A.; Rounaghia, G.; Eshtiagh-Hosseini, H. Determination of non-steroidal anti-inflammatory drugs in urine by hollow-fiber liquid membrane-protected solid-phase microextraction based on sol-gel fiber coating. J. Chromatogr. B 2012, 908, 67-75. [CrossRef]

61. Rezaei, F.; Yamini, Y.; Moradi, M.; Ebrahimpour, B. Solid phase extraction as a cleanup step before microextraction of diclofenac and mefenamic acid using nanostructured solvent. Talanta 2013, 105, 173-1178. [CrossRef]

62. Zhang, H.; Du, Z.; Ji, Y.; Mei, M. Simultaneous trace determination of acidic non-steroidal anti-inflammatory drugs in purified water, tap water, juice, soda and energy drink by hollowfiber-based liquid-phase microextraction and ultra-high pressure liquid chromatography coupled to tandem mass spectrometry. Talanta 2013, 109, 177-184.

63. Manzo, V.; Miró, M.; Richtera, P. Programmable flow-based dynamic sorptive microextraction exploiting an octadecyl chemically modified rotating disk extraction system for the determination of acidic drugs in urine. J. Chromatogr. A 2014, 1368, 64-69. [CrossRef]

(C) 2020 by the authors. Licensee MDPI, Basel, Switzerland. This article is an open access article distributed under the terms and conditions of the Creative Commons Attribution (CC BY) license (http://creativecommons.org/licenses/by/4.0/). 